\title{
On Fine Wine Pricing across Different Trading Venues
}

\author{
Pawel Oleksy $^{\text {a }}$, Marcin Czupryna ${ }^{\text {b }}$ (1) and Michał Jakubczyk ${ }^{\mathrm{c}}$ (])
}

\begin{abstract}
This article examines how selected attributes of Bordeaux fine wines (producer, vintage, quality, bottle size, case, flaws, and transaction volume) affect prices in three types of trading venues: auctions, electronic exchange, and the over-the-counter (OTC) market. The findings indicate a price differentiation across the venues. Wine aging leads to relatively higher prices at auctions than on the electronic exchange or the OTC. There is a nearly linear relationship between prices and wine ratings, the strongest of which is found in the case of auctions. The bottle size effect is mostly positive for supersized formats and is the strongest on an electronic exchange and the weakest at auctions. The transaction volume negatively affects wine prices in all the trading venues. The simulation results facilitate the construction of more realistic trading models and may help traders make more informed decisions on the choice of a trading venue, depending on the wine characteristics. (JEL Classifications: D40, G12, Q14, L66)
\end{abstract}

Keywords: asset pricing, auctions, electronic trading, OTC market, wine.

\section{Introduction}

Fine wines have recently become increasingly popular consumption goods or investment assets, with the market estimated to be worth US\$5 billion per annum (Zimberoff, 2018). Among various economic, technological, or social factors that have driven the rapid development of this market, an important role may be

We are grateful to Karl Storchmann and two anonymous referees for valuable comments and suggestions. We also express our gratitude to Liv-ex Ltd. for providing access to the data. We thank Timothy Harrell for his advice concerning matters of English usage. All remaining errors are the responsibility of the authors. This research was supported by the Ministry of Science and Higher Education within the "Regional Initiative of Excellence" Programme for 2019-2022 (grant no. 021/RID/2018/19).

${ }^{a}$ Cracow University of Economics, Rakowicka 27, 31-510 Cracow, Poland; e-mail: oleksyp@uek.krakow.pl. (corresponding author).

${ }^{\mathrm{b}}$ Cracow University of Economics, Rakowicka 27, 31-510 Cracow, Poland; e-mail: czuprynm@uek. krakow.pl.

${ }^{\mathrm{c}}$ SGH Warsaw School of Economics, Al. Niepodległości 162, 02-554 Warsaw, Poland; e-mail: michal. jakubczyk@sgh.waw.pl.

(C) The Author(s), 2021. Published by Cambridge University Press on behalf of American Association of Wine Economists. This is an Open Access article, distributed under the terms of the Creative Commons Attribution licence (http://creativecommons.org/licenses/by/4.0/), which permits unrestricted re-use, distribution, and reproduction in any medium, provided the original work is properly cited. 
attributed to the digitalization of trade and the evolution of the trading infrastructure. In practice, wine trading takes place in various venues, including traditional or online auctions, multiproduct trading platforms, wine exchanges, specialized online stores, or over-the-counter (OTC) markets. Based on the market microstructure theory (Madhavan, 2000; de Jong and Rindi, 2009) and the market standard implemented by the world's leading fine wine exchange-Liv-ex, all of these venues may be grouped into three major market types: (1) auctions (A) with a bidding mechanism involved in the pricing process, (2) an electronic exchange (L) with an order-driven trading platform, and (3) the OTC market $(\mathrm{O})$ with offexchange bilateral B2B or B2C trades (Czupryna and Oleksy, 2018; Czupryna, Jakubczyk, and Oleksy, 2020a). The venues differ in terms of trading rules, transaction costs, settlement policies, or information distribution and attract various types of traders with diverse trading behavior.

Wine traders themselves do not constitute a homogenous group either. They include both utility-driven and profit-driven traders, who differ in terms of trading motives, scale, and frequency of operations (Dimson, Rousseau, and Spaenjers, 2015; Fernandez-Perez et al., 2019). In the case of retail traders (collectors), the purchasing behavior is largely driven by hedonic motives or emotions, ${ }^{1}$ and trading is likely to occur at auctions, which is where uninformed traders commonly seek to obtain market value for the items they own (Ashenfelter, 1989). In turn, the professional traders are primarily driven by economic motives as opposed to hedonic ones, so they are more likely to trade on an organized wine exchange that provides the opportunity for continuous and anonymous trading, contract standardization, cost efficiency, higher market liquidity, or volatility reduction. For instance, Liv-ex requirements limit the exchange membership to professional buyers and sellers and exclude retail traders from the market (Liv-ex, 2019). Additionally, professional wine traders and investors trade in the OTC market, where they interact with both other wine-based commercial operators (B2B) or hedonically motivated end-users (B2C).

The combination of the two factors mentioned previously (the traders differing in their motivations and various trading venues attracting diverse types of traders) can lead to different valuations of particular fine wine attributes because some of those attributes may be irrelevant to one group of traders yet attract special attention from another. Therefore, considering the possible inter-venue differences in wine pricing is highly important when striving to understand the price impact of various wine characteristics. It may help to understand traders' strategies or provide salient advice regarding the choice of a trading venue while also aiding the development of more realistic (simulation) models of such markets.

\footnotetext{
${ }^{1}$ This does not imply that the financial motive is not important for them, just that it is simply not a primary driver of their trading decisions.
} 
While much of the related literature refers to prices from one particular type of trading venue (Ashenfelter, 1989; Jaeger and Storchmann, 2011; Cardebat, Figuet, and Paroissien, 2014; Cardebat et al., 2017; Czupryna, Jakubczyk, and Oleksy, 2020b), the analyzes of price behavior in a multimarket setting with a clear separation of trading venues have received less attention. Most of the studies dissect the markets intuitively by distinguishing between auction and dealer prices (Dimson, Rousseau, and Spaenjers, 2015), between auction, dealer, and wholesale prices (Ashenfelter and Storchmann, 2010), or between recommended retail prices and market prices (Oczkowski, 2016). We fill this gap by providing the results of a systematic analysis of the price impact of various wine characteristics across distinctly specified trading venues.

Our contribution to the existing literature is threefold. First, we implement a conceptual framework rooted in the market microstructure theory to examine differences in wine pricing in a multimarket setting. In particular, we specify a single formalized model with parameters that are both common across trading venues and specific to individual types, which allows us to estimate the price impacts of all the predefined wine features at the same time. Most of the results confirm our baseline intuitions - for instance, the higher the quality of wine, the higher the price it obtains. However, some results are less intuitive-for instance, the age (group) effect imparts relatively higher price premiums for young wines than for those of medium age.

Second, to ensure data comparability across respective venues, a unified dataset of wine prices has been used. It has been provided by one data provider - the Liv-ex exchange, which collects such data continuously and makes it available to all exchange traders.

Third, we employ a Bayesian approach to overcome the problem of sparse and non-synchronous data, which is typical for the fine wine market. Although hedonic regressions (Oczkowski, 2016; Cardebat et al., 2017; Faye and Le Fur, 2019; Niklas and Rinke, 2020) or repeat-sales regressions (Burton and Jacobsen, 2001; Masset and Weisskopf, 2018) are commonly applied to investigate the price behavior of fine wines, we believe that the Bayesian approach corresponds better to our dataset.

For the purpose of our analysis, we consider wine attributes that are widely confirmed to be significant price determinants, such as producer reputation, quality of wine, wine age, case packaging, transaction volume (Schamel and Anderson, 2003; Oczkowski, 2016; Cardebat et al., 2017) or bottle formats (Outreville, 2011). Producer reputation affects traders' decisions in general by evoking strong associations with product quality and its perceived value. As is suggested by a theoretical model of Shapiro (1983), products of quality that are difficult to evaluate prior to purchase (such as wines) may provide a price premium for producers with a good reputation. Although all wine producers under consideration in this study belong to the same reputation class (Bordeaux's First Growth), differences 
in traders' preferences and attitudes towards the brand may translate into differences in wine prices. In extreme cases, unchecked exuberance in trader behavior may drive a rapid escalation in prices, ultimately leading to speculative bubbles, as was the case for Lafite Rothschild wines between 2009 and 2012 (Breeden and Liang, 2017; Tolhurst, 2019).

Fine wine is a high-quality product. Nevertheless, its quality evolves over time, and periodic evaluations are carried out to provide traders with information on the current or expected quality of wines from particular vintages. In this respect, expert endorsements have become the popular (Storchmann, 2012; Luxen, 2018), albeit imperfect (Cardebat, Figuet, and Paroissien, 2014) proxy for the quality of wine, and the price-rating relationship has been revealed to be mostly positive (Jones and Storchmann, 2001; Masset, Weisskopf, and Cossutta, 2015) and nonlinear (Cyr, Kwong, and Sun, 2019). Importantly, marketing literature indicates two major dimensions in product quality evaluation: the objective and perceived quality (Wankhede and Dabade, 2010; Boyer and Verma, 2009). While the former refers to objectively measurable product characteristics, the latter constitutes a customer's subjective judgment of the product quality, based on its intrinsic and extrinsic features (Espejel, Fandos, and Flavian, 2007). Therefore, differences in assessing the perceived quality of wine may affect trading decisions and produce both intravenue or inter-venue differences in wine pricing.

Due to the prolonged maturation, as well as the progressive scarcity of product stocks, fine wines tend to command higher prices as they age (Jones and Storchmann, 2001; Ashenfelter, 2008). However, the price-age relationship reveals non-linear price patterns over the entire life-cycle of high-quality wines, as indicated by an illustrative model of Dimson, Rousseau, and Spaenjers (2015). In particular, when fine wine begins to provide more of a collectible value than a consumption value, a non-financial ownership dividend becomes a primary driver of price appreciation. Hence, the wine age effect seems to have a particularly strong impact on traders driven by emotional motivations, who regularly trade at auctions and search for unique bottles of old wines. As revealed by Georgantzís and Tisserand (2019), risk-taking is positively associated with a willingness to pay for old wine.

The bottle size effect may influence wine pricing in two ways: first, through the product atypicality itself (Blijlevens et al., 2012) and the generally lower affinity of customers towards non-standard bottle sizes, as compared to a standard $750 \mathrm{ml}$ volume (Brunke et al., 2009), and second, through the scale of deviation from a regular size (Chandon and Ordabayeva, 2009). Naturally, an increase in package size entails an increase in product prices. However, the price-size relationship exhibits non-linear patterns with significant discounts for larger-sized products (Fox and Melser, 2014). Status signaling (Dubois, Rucker, and Galinsky, 2012), compromise and attraction effects (Carroll and Vallen, 2014), the context effect (Prelec, Wernerfelt, and Zettelmeyer, 1997), or the power law of sensation (Stevens, 1986) may provide possible explanations of this phenomenon. Empirical studies on the bottle size effect in the fine wine market indicate higher unit costs of an empty 
bottle (Outreville, 2011), progressive (supply-based) scarcity effects (Lynn, 1989; Di Vittorio and Ginsburgh, 1996; Outreville, 2011), the need for uniqueness or recognition of social status (Terrien and Steichen, 2008; van Herpen, Pieters, and Zeelenberg, 2014), or slower oxidation and quality deterioration (Morozova, Schmidt, and Schwack, 2015) to be factors that may contribute to relatively greater price premiums for large bottle formats.

As is true of other consumer products, wine packaging plays an important role in both consumers' purchasing decisions (e.g., Garber, 1995; Wang, 2013) and product logistics (e.g., Madhani, 2017). Similarly to the bottle size effect, an increase in transaction volume (number of units in a pack) entails appropriate price adjustment (Fox and Melser, 2014). Complete cases provide greater confidence in wine authenticity or may have a trophy value to investors who are likely to pay a price premium for this wine attribute (Cardebat et al., 2017).

All the selected wine attributes are subject to analysis in terms of their impact on price formation at auctions, on the electronic exchanges, and in the OTC market, respectively. Using the analogy to financial markets and product pairs, such as futures and forward contracts (Hull, 2018), we postulate that higher prices for the typical, standard products (typical bottle size, case packaging, maturity), relative to the non-standard products, are observed on electronic exchanges rather than at auctions or in the OTC market. Due to no clear-cut indications from market mechanisms and the characteristics of market participants involved, no unambiguous hypotheses may be put forward, so the emphasis is put on an empirical, exploratory analysis.

The remainder of this article is organized as follows: Section II describes the dataset and its structure. Section III details the methodology, including the model specification and estimation procedure. Section IV sets out the results of the study, and Section $\mathrm{V}$ provides a concise discussion of their implications. The conclusion is given in Section VI.

\section{Data}

In our analysis, we have used a dataset of 113,761 transaction prices ${ }^{2}$ from the three different trading venues (Liv-ex, Auctions, OTC). The data covers vintages from 1974 to 2013 and a trading period of 11 years (2005-2015) for vintages of 19922013, plus one additional year (June 2014-June 2015) for vintages of 1974-1991, for reasons of data availability. All price data has been provided by the Liv-ex exchange and is available for authorized users of the Liv-ex platform while trading. All prices are harmonized, such that all taxes, fees, and buyer premiums

\footnotetext{
${ }^{2}$ We originally considered a dataset with 114,563 transactions, although $0.7 \%$ was removed due to (partially) incomplete data.
} 
Table 1

Basic Statistics of the Dataset

\begin{tabular}{|c|c|c|c|c|}
\hline $\begin{array}{l}\text { Trading } \\
\text { Venue }\end{array}$ & $\begin{array}{l}\text { Mean Pricel } \\
\quad 750 \mathrm{ml}\end{array}$ & $\begin{array}{l}\text { Mean Bottle } \\
\text { Volume }(\mathrm{ml})\end{array}$ & $\begin{array}{l}\text { Mean Quantity of } \\
\text { Bottles per Trade }\end{array}$ & $\begin{array}{l}\text { Percent in } \\
\text { Cases }\end{array}$ \\
\hline \multicolumn{5}{|c|}{ Haut Brion } \\
\hline Liv-ex & 269.97 & 788.53 & 20.70 & 99.25 \\
\hline Auctions & 279.11 & 1097.59 & 10.00 & 68.96 \\
\hline OTC & 318.28 & 812.45 & 16.45 & 86.45 \\
\hline \multicolumn{5}{|c|}{ Lafite Rothschild } \\
\hline Liv-ex & 529.46 & 788.55 & 20.77 & 98.14 \\
\hline Auctions & 669.49 & 1122.92 & 9.33 & 62.92 \\
\hline OTC & 611.41 & 830.93 & 17.02 & 89.17 \\
\hline \multicolumn{5}{|c|}{ Latour } \\
\hline Liv-ex & 409.39 & 788.84 & 19.60 & 98.27 \\
\hline Auctions & 425.67 & 1106.50 & 9.69 & 66.10 \\
\hline OTC & 472.32 & 800.61 & 15.44 & 88.63 \\
\hline \multicolumn{5}{|c|}{ Margaux } \\
\hline Liv-ex & 331.31 & 786.12 & 18.75 & 98.96 \\
\hline Auctions & 367.63 & 1117.95 & 9.41 & 64.93 \\
\hline OTC & 366.81 & 792.57 & 15.93 & 87.07 \\
\hline \multicolumn{5}{|c|}{ Mouton Rothschild } \\
\hline Liv-ex & 301.67 & 829.18 & 21.92 & 97.94 \\
\hline Auctions & 339.64 & 1313.49 & 9.43 & 62.25 \\
\hline OTC & 332.12 & 901.44 & 17.56 & 81.20 \\
\hline
\end{tabular}

are excluded. Aside from transaction prices, for modeling, we have also made use of the Liv-ex 50 market index, which is one of the most recognizable Liv-ex family indices. ${ }^{3}$ Detailed information on the data structure is presented in Table 1.

The statistics presented in Table 1 highlight the role of electronic trading in improving market efficiency (e.g., the lowest prices per $750 \mathrm{ml}$ of wine traded) and introducing a kind of trade standardization (average bottle size close to standard size and a high percentage of cases used in trading). The mean quantities of bottles per trade indicate that the Liv-ex exchange and the OTC market are dominated by professional wine traders who place relatively large orders, as compared to auctions. The latter seems to be mostly occupied by retail traders or investors, who, in turn, trade larger bottle formats on average.

\footnotetext{
${ }^{3}$ Liv-ex 50 index tracks the daily price movements of the ten most recent vintages of the First Growth wines from Bordeaux (excluding en primeur) considered in this study.
} 
Table 2

Quality Categories and Quantities Sold in Respective Venues

\begin{tabular}{|c|c|c|c|c|c|c|c|}
\hline \multirow{2}{*}{$\begin{array}{l}\text { Parker } \\
\text { Points }\end{array}$} & \multirow{2}{*}{$\begin{array}{c}\text { Quality } \\
\text { Category }\end{array}$} & \multicolumn{3}{|c|}{ Total Quantity } & \multicolumn{3}{|c|}{ Total Number of Lots } \\
\hline & & Liv-ex & Auctions & OTC & Liv-ex & Auctions & OTC \\
\hline $96-100$ & 5 & 59,181 & 93,909 & 214,463 & 3,379 & 10,082 & 14,810 \\
\hline $90-95$ & 4 & 76,569 & 98,083 & 278,953 & 4,068 & 10,179 & 14,230 \\
\hline $80-89$ & 3 & 186,985 & 186,626 & 436,007 & 8,200 & 19,335 & 25,446 \\
\hline $70-79$ & 2 & 1,608 & 10,267 & 22,518 & 110 & 1,215 & 2,700 \\
\hline $0-69$ & 1 & 0.00 & 14.00 & 20.00 & 0 & 3 & 4 \\
\hline
\end{tabular}

Besides the Liv-ex dataset, we have additionally used the information on damaged wine bottles at auctions organized by Sotheby's Department of Wine $\&$ Spirits. This information, usually contained in lot descriptions in the catalogs available to buyers before particular auctions, has been used as an informative prior for the percentage share of damaged bottles. All current and previous catalogs are available on Sotheby's official website in the Results section. The set of catalogs covers wine auctions held on the following dates: 2015-01-28, 2014-11-19, 2014-06-21, 2014-04-30, 2013-10-04, 2013-09-18, 2013-02-27, 2012-11-14, 201203-21.

Moreover, in order to determine the quality of wine, we have used the system of Parker points aggregated at a regional level (Graves: Haut-Brion; Margaux: Margaux; and Pauillac: Mouton-Rothschild, Latour, Lafite Rothschild), as elaborated in The Wine Advocate Vintage Guide 1970-2015 (Robert Parker Wine Advocate, 2018). The detailed information on the total quantity (after converting different bottle sizes to $750 \mathrm{ml}^{\text {volumes }}{ }^{4}$ ) and the total number of lots sold in the three venues, under each of the five Parker classifications, is presented in Table 2.

\section{Methodology}

To estimate the factors determining the wine price, the following assumptions have been made to specify the data generation process. It is assumed that at every moment $t$ (which is the number of the consecutive month of the analysis data ${ }^{5}$ ), a value of a given wine (identified by producer $p$, vintage $v$, and trading venue $m)-V_{t}^{p v}(m)$

\footnotetext{
${ }^{4}$ The conversion procedure was conducted in the following way: for each transaction, the bottle size (in $\mathrm{ml}$ ) has been divided by $750 \mathrm{ml}$ and then multiplied by the number of bottles sold in this transaction (e.g., $1,500 \mathrm{ml} / 750 \mathrm{ml}^{*} 6$ bottles results in quantity of 12 ). The total quantity is the sum of the conversion results. Because the dataset also contained bottles that are not a simple multiple or fraction of $750 \mathrm{ml}$ (e.g., $5,000 \mathrm{ml}$ ), the quantity numbers have been rounded in such cases.

${ }^{5}$ The data were aggregated to one-month intervals as only one-month values are available for the historical Liv-ex data.
} 
Figure 1

\section{The Liv-ex 50 Index}

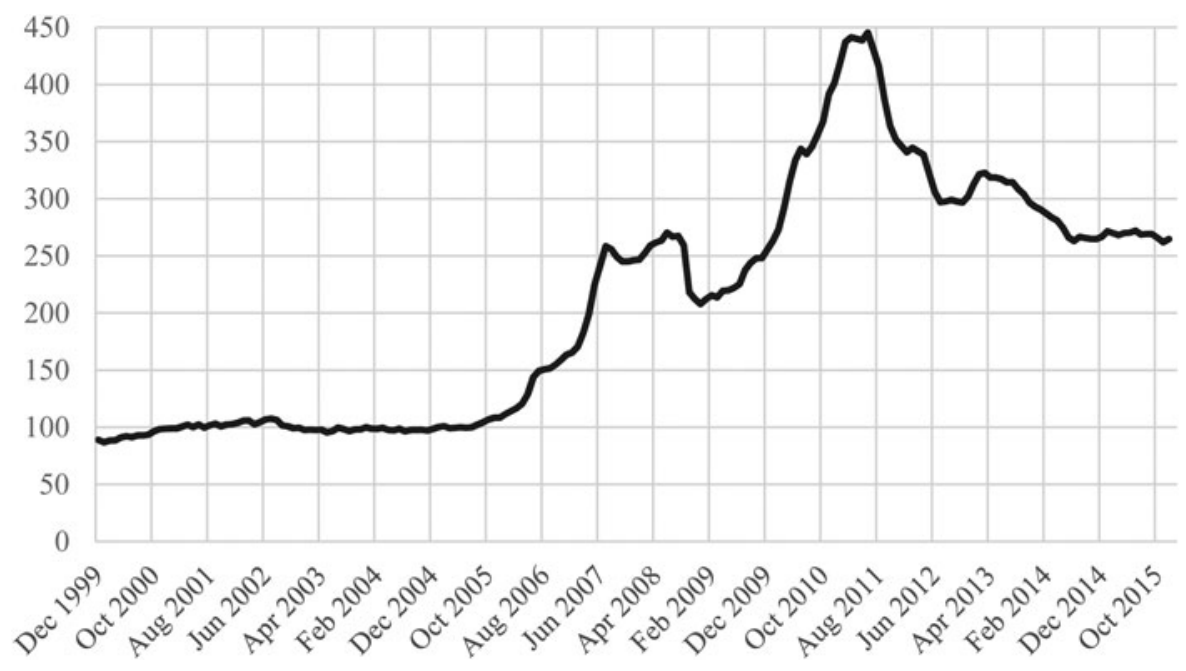

changes in proportion to the Liv-ex 50 index value $-I_{t}$ (illustrated in Figure 1):

$$
V_{t}^{p v}(m)=\beta(m) \times \beta^{p} \times \beta^{v}(m) \times \beta^{q}(m) \times I_{t}
$$

The parameter $\beta(m)$ represents the trading-venue effect. Parameter $\beta^{p}$ represents the producer effect and is assumed to be trading venue independent as all producers belong to the same 1855 classification group-First Growth (the value of this parameter for the selected producer-Margaux - is set to 1 to ensure that the model is identifiable). The trading venue-dependent parameter $\beta^{v}(m)$ represents the age group effect. To estimate this type of age effect, 40 vintages under consideration were first divided into five equal periods (eight years each, where "1" represents the oldest eight vintages, and " 5 " represents the youngest eight vintages). For each period and venue, a separate parameter value was estimated (although the value of the parameters for the third (middle) period was set to 1 , for the same reasons as in the case of the producer effect). Parameter $\beta^{q}(m)$ represents the quality effect.

The reason for controlling for index value is its variability (mean value equals 255.7, and the standard deviation is equal to 84.24 in the period under consideration). Those changes automatically translate into changes in monthly index returns, amounting to $0.77 \%$ on average (with a standard deviation of $3.49 \%$ ).

We also decided not to impose a priori any structure on the relations among the $\beta^{v}(m)$ and $\beta^{q}(m)$ parameters. 
The values defined in Equation (1) are extended to additionally include the remaining determinants of wine prices recognized in the dataset. This leads to the following equation 6 :

$$
\begin{aligned}
\ln \left(\tilde{V}^{w}\right)= & \ln \left(V_{t}^{p v}(m)\right)+\eta(m) \times \ln \left(V o l^{w}\right)+\left(\gamma_{0}(m) \times N S B+\gamma_{1}(m) \cdot B S R\right)+\varphi \\
& \times F L A W+\zeta(m) \times C A S E+\delta(m) \times t,
\end{aligned}
$$

where $w$ indexes the single transaction. We consider the following variables: $\tilde{V}^{w}$ is the value of a hypothetical $750 \mathrm{ml}$ of wine, $V o l^{w}$ - transaction volume (transformed into a multiple of $750 \mathrm{ml}$ of wine traded in a single transaction), NSB (non-standard bottle) - a binary variable capturing the atypicality sub-effect and assuming the value 0 for $750 \mathrm{ml}$ bottle and 1 otherwise; $B S R$ (Bottle Size Ratio) - a variable capturing the size deviation sub-effect, defined as the ratio of the bottle size (in ml) to $750 \mathrm{ml}$, FL AWa binary variable assuming the value 0 for lots in perfect conditions and 1 otherwise; $C A S E$ - a binary variable assuming the value 1 for the standard 6- or 12-bottle cases and 0 otherwise; $t$ is the number of the consecutive month.

We have introduced the following parameters and denoted an explicit dependence on a trading venue by $(m)$ notation: $\eta(m)$ - price elasticity; $\gamma_{0}(m)$ and $\gamma_{1}(m)$ - bottle size sub-effects: an intercept and a slope, respectively; $\varphi$ - flaw effect $^{7} ; \zeta(m)$ - case effect; $\delta(m)$ - age (aging) effect.

Additionally, for duty paid transactions (relevant only for a marginal number of Liv-ex transactions), we have controlled for the duty effect:

$$
\ln \left(V^{w}\right)=\ln \left(\tilde{V}^{w}\right)+\kappa \times D P,
$$

where $D P$ is a binary variable, which takes the value 1 if duty was paid and 0 otherwise.

Finally, the observed transaction price $\left(P^{w}\right)$ has been modeled as:

$$
P^{w}=V^{w}+V^{w} \times \varepsilon(m)
$$

Idiosyncratic trading-venue dependent noise is represented by $\varepsilon(m)$. We assumed a generalized t-Student distribution with degrees of freedom to be estimated. First, it is symmetric and therefore makes it easier not to confuse the impact of parameters on the spread and the expected value. Second, it allows for a separate examination

\footnotetext{
${ }^{6}$ Logarithms have been used for transforming from an originally multiplicative to a simpler additive form of Equation (2). Using the approximation, it will be possible to directly interpret the values of estimated parameters as a percentage change in the value.

${ }^{7}$ Since only the data on the Liv-ex and OTC transactions contains such information, we only estimate and control for the general flaw effect without differentiating between trading venues.
} 
of the impact on the spread (via changing the scale parameter) and fat-tails (via changing the degrees of freedom).

For the auction market, the information concerning whether a bottle was damaged in a specific transaction was not present in the dataset. Instead, we have assumed that damage is present, albeit unobserved, with some probability $p^{\varphi}(A)$ (to be estimated).

The model, as specified previously, has subsequently been estimated utilizing the Bayesian approach (Kruschke, 2014). This selection has been motivated by two factors. First, especially given the missing data (lack of information about any damage at auction), the Bayesian approach allows for more flexibility in constructing the model specification and using prior beliefs for the frequency of damaged bottles at auctions. The weak informative prior was chosen based on the textual analysis of lot descriptions in Sotheby's catalogs. For all other parameters, noninformative priors have been used. Second, the Bayesian approach has been found to be more appropriate for a dataset that contains a complete list of actual transactions, rather than a random sample (and, in the most frequent approach used typically in the hedonic regression, the results of the analysis, e.g., the confidence intervals, are interpreted in terms of the outcomes of repeated studies).

The posterior distributions have been estimated with Markov Chain Monte Carlo in the JAGS/R environment. In the simulation, 1,000 adapt, 10,000 burn-in, and 5,000 results-generating iterations have been used with four chains initiated with random values (no thinning has been applied). Medians of the posterior distributions have been used as point estimates; the $95 \%$ credible intervals have been constructed with the use of $2.5 \%$ and $97.5 \%$ percentiles. The model convergence has been tested with potential scale reduction factor (PSRF) statistics. No problems have been identified for any parameters apart from $\varphi$, and $p^{\varphi}(A)$. This is due to missing markings of bottle damages for transactions at the auction venue. These parameters remained in the model to ensure comparability of the results for the auction market with the Liv-ex and the OTC markets.

\section{Results}

The $\beta(m)$ parameter in this model is intended to capture a general trading venue effect. The higher the level of $\beta(m)$ for a particular wine, the greater (proportionally) the unobserved value of that wine. Medians of the posterior distributions, presented in Table 3, reveal that trading at auctions involves relatively higher values of wines in comparison to other trading venues. In general, this relationship may be referred to as an inequality: $\beta(A)>\beta(L)>\beta(O)$. The values of $\beta$ parameters, after controlling for the other effects, constitute the ultimate price of fine wines.

The results on the producer effect presented in Table 4 indicate that Lafite Rothschild is the most expensive and Haut Brion is the most inexpensive among 
Table 3

Trading Venue Effect

\begin{tabular}{lcccccc}
\hline & Median & $P_{2.5}$ & $P_{97.5}$ & SD & AC.10 & PSRF \\
\hline $\ln (\beta(A))$ & -0.086 & -0.105 & -0.067 & 0.01 & 0.869 & 1.004 \\
$\ln (\beta(L))$ & -0.093 & -0.141 & -0.036 & 0.027 & 0.947 & 1.083 \\
$\ln (\beta(O))$ & -0.274 & -0.287 & -0.259 & 0.007 & 0.822 & 1.006 \\
$\ln (\beta(L))-\ln (\beta(O))$ & 0.18 & 0.129 & 0.233 & 0.027 & 0.935 & 1.07 \\
$\ln (\beta(A))-\ln (\beta(L))$ & 0.008 & -0.05 & 0.059 & 0.027 & 0.933 & 1.066 \\
\hline
\end{tabular}

Table 4

Producer Effect

\begin{tabular}{lcccccc}
\hline & Median & $P_{2.5}$ & $P_{97.5}$ & SD & AC.10 & PSRF \\
\hline $\ln \left(\beta^{p}(1)\right)$ & -0.335 & -0.342 & -0.329 & 0.004 & 0.391 & 1.001 \\
$\ln \left(\beta^{p}(2)\right)$ & -0.297 & -0.303 & -0.291 & 0.003 & 0.438 & 1.002 \\
$\ln \left(\beta^{p}(4)\right)$ & -0.014 & -0.021 & -0.007 & 0.003 & 0.393 & 1.002 \\
$\ln \left(\beta^{p}(5)\right)$ & 0.32 & 0.313 & 0.326 & 0.003 & 0.478 & 1.003 \\
$\ln \left(\beta^{p}(2)\right)-\ln \left(\beta^{p}(1)\right)$ & 0.038 & 0.033 & 0.044 & 0.003 & 0.001 & 1 \\
$\ln \left(\beta^{p}(5)\right)-\ln \left(\beta^{p}(4)\right)$ & 0.333 & 0.329 & 0.338 & 0.002 & 0.005 & 1 \\
\hline
\end{tabular}

Notes: 1 - Haut Brion, 2 - Mouton Rothschild, 3 - Margaux, 4 - Latour, 5 - Lafite Rothschild.

the wines analyzed, with approximately $65 \%$ difference between their median prices. In general, based upon the empirical model, the strength of the producer effect may be ranked as follows.

$$
\begin{aligned}
& \beta^{p}(\text { Lafite Rothschild })>\beta^{p}(\text { Margaux })>\beta^{p}(\text { Latour })>\beta^{p}(\text { MoutonRothschild }) \\
& \quad>\beta^{p}(\text { HautBrion })
\end{aligned}
$$

Apart from Margaux and Latour, which have switched places in the ranking, these findings correspond to the descriptive statistics provided in Table 1 for the mean prices of $750 \mathrm{ml}$ of wine. The reason for this switch is the different distribution of transactions with a different quality category for those two producers. The higher mean price of Latour is due to relatively better Parker points as compared to Margaux, rather than being down to the producer effect.

The age effect is examined from two perspectives: wine aging and age grouping. In the first case, the effect measures the change in value between the first and the following (observed later) transactions for a particular wine. As anticipated, the estimated parameters (Table 5) reveal a slight, yet significant, influence of wine aging, albeit with apparent differences across trading venues.

Alongside this, the age effect may produce price premiums for wines belonging to a specific age group. Such groups may be determined, for instance, based on a different phase of the wine's life cycle (maturing) while being traded. Technically, in this 
Table 5

Age (Aging) Effect

\begin{tabular}{lcccccc}
\hline & Median & $P_{2.5}$ & $P_{97.5}$ & $S D$ & AC.10 & PSRF \\
\hline$\delta(A)$ & 0.000068 & 0.000064 & 0.000073 & 0.000002 & 0.657 & 1.001 \\
$\delta(L)$ & 0.000027 & 0.000021 & 0.000032 & 0.000003 & 0.489 & 1.002 \\
$\delta(O)$ & 0.000037 & 0.000034 & 0.000040 & 0.000002 & 0.432 & 1.002 \\
\hline
\end{tabular}

Table 6

Age (Group) Effect

\begin{tabular}{lcccccc}
\hline & Median & $P_{2.5}$ & $P_{97.5}$ & SD & AC.10 & PSRF \\
\hline \multicolumn{7}{c}{ Auctions } \\
\hline $\ln \left(\beta^{v=1}(A)\right)$ & 0.091 & 0.062 & 0.119 & 0.014 & 0.168 & 1 \\
$\ln \left(\beta^{v=2}(A)\right)$ & 0.479 & 0.459 & 0.5 & 0.01 & 0.249 & 1.001 \\
$\ln \left(\beta^{v=4}(A)\right)$ & 0.199 & 0.193 & 0.206 & 0.003 & 0.132 & 1.001 \\
$\ln \left(\beta^{v=5}(A)\right)$ & 0.199 & 0.187 & 0.212 & 0.006 & 0.097 & 1 \\
\hline & & Electronic Exchange (Liv-ex) & & \\
\hline $\ln \left(\beta^{v=1}(L)\right)$ & 0.241 & 0.011 & 0.489 & 0.122 & 0.007 & 1 \\
$\ln \left(\beta^{v=2}(L)\right)$ & 0.724 & 0.631 & 0.822 & 0.049 & 0.014 & 1 \\
$\ln \left(\beta^{v=4}(L)\right)$ & 0.129 & 0.117 & 0.142 & 0.006 & 0.274 & 1 \\
$\ln \left(\beta^{v=5}(L)\right)$ & 0.114 & 0.1 & 0.129 & 0.007 & 0.395 & 1.001 \\
\hline & \multicolumn{7}{c}{ OTC Market } \\
\hline $\ln \left(\beta^{v=1}(O)\right)$ & 0.084 & 0.049 & 0.117 & 0.017 & 0.068 & 1 \\
$\ln \left(\beta^{v=2}(O)\right)$ & 0.289 & 0.265 & 0.312 & 0.012 & 0.084 & 1 \\
$\ln \left(\beta^{v=4}(O)\right)$ & 0.185 & 0.179 & 0.192 & 0.003 & 0.229 & 1 \\
$\ln \left(\beta^{v=5}(O)\right)$ & 0.157 & 0.148 & 0.166 & 0.004 & 0.555 & 1 \\
\hline
\end{tabular}

Notes: 1-vintages 1974-1981, 2 - vintages 1982-1989, 3 - vintages 1990-1997, 4 - vintages 1998-2005, 5 - vintages 2006-2013

case, wines have been grouped into five groups, depending on the age when the first transaction within the observation period occurred. In particular, wines in category 5 have been observed since their release, wines in category 4 are at most seven years old at the beginning of the observation period, wines in category 3 are at most 15 years old at the beginning of the observation period, and so forth. The estimates presented in Table 6 and illustrated in Figure 2 demonstrate a slight novelty premium for younger vintages (age groups 5 and 4, covering wines aged 3.2 and 8.5 years on average, respectively) and relatively large maturity premiums for wines reaching maturity (age group 2, with an average age of 24.5 years), although this maturity premium attenuates over time.

Wine quality, proxied by Parker points aggregated at a regional level, is positively and significantly related to fine wine prices in all of the trading venues (Table 7). 
Figure 2

\section{Age (Group) Effect}

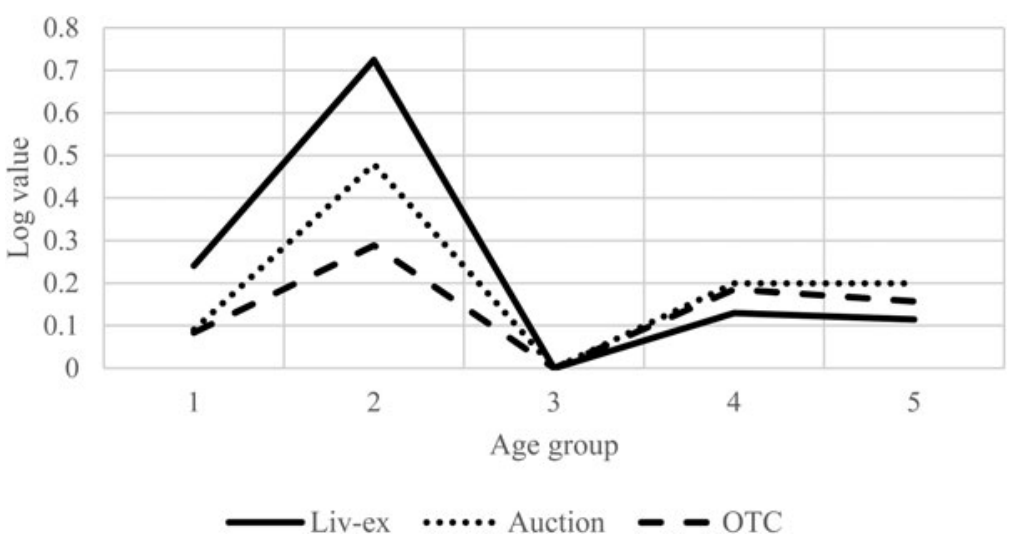

Table 7

Quality Effect

\begin{tabular}{|c|c|c|c|c|c|c|}
\hline & Median & $P_{2.5}$ & $P_{97.5}$ & $S D$ & AC. 10 & PSRF \\
\hline \multicolumn{7}{|c|}{ Auctions } \\
\hline $\ln \left(\beta^{q=1}(A)\right)$ & -0.581 & -0.9 & -0.251 & 0.165 & 0.009 & 1 \\
\hline $\ln \left(\beta^{q=2}(A)\right)$ & -0.08 & -0.098 & -0.062 & 0.009 & 0.046 & 1.001 \\
\hline $\ln \left(\beta^{q=4}(A)\right)$ & 0.353 & 0.345 & 0.36 & 0.004 & 0.07 & 1 \\
\hline $\ln \left(\beta^{q=5}(A)\right)$ & 0.765 & 0.757 & 0.772 & 0.004 & 0.101 & 1 \\
\hline \multicolumn{7}{|c|}{ Electronic Exchange (Liv-ex) } \\
\hline $\ln \left(\beta^{q=1}(L)\right)$ & -0.38 & -61.373 & 64.277 & 31.922 & 0.003 & 1 \\
\hline $\ln \left(\beta^{q=2}(L)\right)$ & -0.041 & -0.092 & 0.01 & 0.026 & 0.024 & 1.001 \\
\hline $\ln \left(\beta^{q=4}(L)\right)$ & 0.335 & 0.325 & 0.345 & 0.005 & 0.028 & 1 \\
\hline $\ln \left(\beta^{q=5}(L)\right)$ & 0.681 & 0.67 & 0.693 & 0.006 & 0.092 & 1 \\
\hline \multicolumn{7}{|c|}{ OTC Market } \\
\hline $\ln \left(\beta^{q=1}(O)\right)$ & -0.363 & -0.567 & -0.14 & 0.109 & 0.003 & 1 \\
\hline $\ln \left(\beta^{q=2}(O)\right)$ & -0.081 & -0.092 & -0.071 & 0.005 & 0.1 & 1 \\
\hline $\ln \left(\beta^{q=4}(O)\right)$ & 0.329 & 0.323 & 0.334 & 0.003 & 0.044 & 1 \\
\hline $\ln \left(\beta^{q=5}(O)\right)$ & 0.756 & 0.751 & 0.762 & 0.003 & 0.108 & 1.001 \\
\hline
\end{tabular}

Notes: Intervals for Parker points: $1-0-69$ pts., $2-70-79$ pts., $3-80-89$ pts., $4-90-95$ pts., $5-96-100$ pts. 
Table 8

Bottle Size Effect

\begin{tabular}{lcccccc}
\hline & Median & $P_{2.5}$ & $P_{97.5}$ & $S D$ & AC.10 & PSRF \\
\hline$\gamma_{0}(A)$ & -0.044 & -0.056 & -0.032 & 0.006 & 0.171 & 1 \\
$\gamma_{0}(L)$ & -0.103 & -0.138 & -0.069 & 0.018 & 0.248 & 1.005 \\
$\gamma_{0}(O)$ & -0.073 & -0.086 & -0.061 & 0.007 & 0.163 & 1.003 \\
$\gamma_{1}(A)$ & 0.031 & 0.028 & 0.034 & 0.002 & 0.334 & 1 \\
$\gamma_{1}(L)$ & 0.065 & 0.051 & 0.079 & 0.007 & 0.629 & 1.032 \\
$\gamma_{1}(O)$ & 0.055 & 0.05 & 0.06 & 0.002 & 0.395 & 1.007 \\
\hline
\end{tabular}

Figure 3

Price Sensitivity to Various Bottle Size across Trading Venues

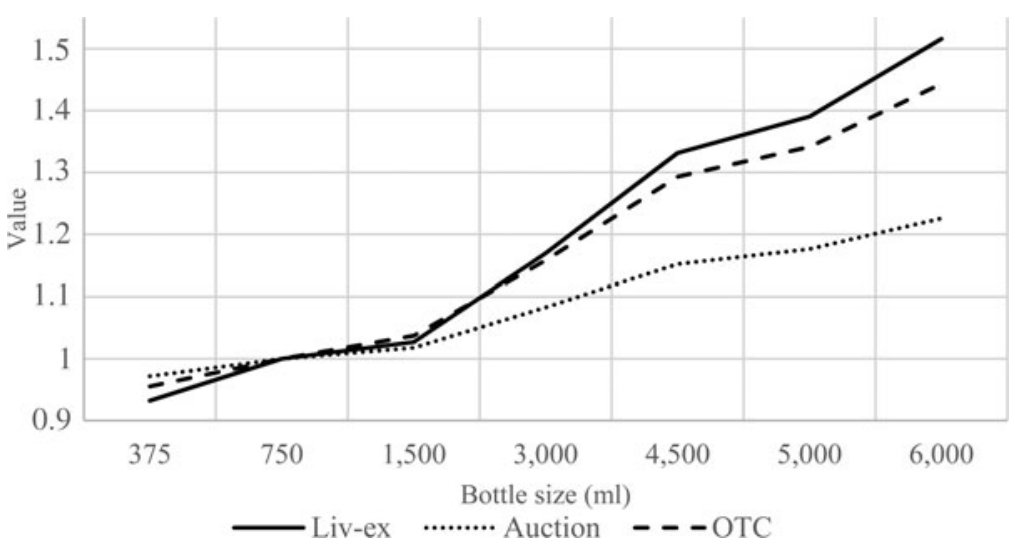

Remarkably, the strongest quality effect is observed at auctions, where bidders strongly appreciate top wines (graded 96+) and depreciate wines graded below 69 points.

Furthermore, trading non-standard bottle formats, that is, different from $750 \mathrm{ml}$, provides significant price discounts (Table 8 ). The strongest atypicality sub-effect is likely to occur on the electronic wine exchange, followed by the OTC market and then auctions (as estimated by $\gamma_{0}(m)$ ). Also, the size deviation from the standard bottle size translates into an additional price correction. Depending on the bottle size, the size deviation sub-effect may offset or even outweigh the atypicality subeffect. For instance, in the case of one 3-liter jeroboam offered on Liv-ex, the total bottle size effect may translate into a total price increase of $15.7 \%$.

In addition, the price sensitivity to different non-standard bottle sizes traded in specific trading venues has been illustratively depicted in Figure 3. The angles of inclination of particular curves indicate the greatest sensitivity of the Liv-ex prices to changes in bottle sizes. 
Table 9

The Transaction Volume Effect $(\eta)$ and the Case Effect $(\zeta)$

\begin{tabular}{lcccccc}
\hline & Median & $P_{2.5}$ & $P_{97.5}$ & $S D$ & AC.10 & PSRF \\
\hline$\eta(A)$ & -0.08 & -0.086 & -0.073 & 0.003 & 0.768 & 1.002 \\
$\eta(L)$ & -0.014 & -0.021 & -0.008 & 0.003 & 0.661 & 1.001 \\
$\eta(O)$ & -0.022 & -0.025 & -0.019 & 0.002 & 0.508 & 1 \\
$\zeta(A)$ & 0.086 & 0.076 & 0.096 & 0.005 & 0.577 & 1.002 \\
$\zeta(L)$ & -0.106 & -0.148 & -0.065 & 0.021 & 0.922 & 1.078 \\
$\zeta(O)$ & 0.067 & 0.058 & 0.076 & 0.004 & 0.598 & 1.002 \\
\hline
\end{tabular}

Table 10

Price Dispersion Estimates

\begin{tabular}{lccclll}
\hline & Median & Lower95 & Upper95 & \multicolumn{1}{c}{ SD } & AC.10 & PSRF \\
\hline$\tau(A)$ & 23.705 & 22.798 & 24.683 & 0.48 & 0.348 & 1.002 \\
$\tau(L)$ & 18.055 & 17.388 & 18.721 & 0.341 & 0.033 & 1.001 \\
$\tau(O)$ & 19.706 & 19.317 & 20.109 & 0.201 & 0.064 & 1 \\
$d f(A)$ & 2.927 & 2.816 & 3.054 & 0.06 & 0.2 & 1 \\
$d f(L)$ & 5.62 & 5.118 & 6.133 & 0.259 & 0.073 & 1.001 \\
$d f(O)$ & 4.506 & 4.336 & 4.683 & 0.088 & 0.108 & 1 \\
\hline
\end{tabular}

Notes: $\tau$-precision, $d f$-degrees of freedom

The negative sign for $\eta(\mathrm{m})$ coefficients across all trading venues confirms an inverse relationship between the wine price and transaction volume. As shown in Table 9, the highest elasticity (in terms of absolute value) is observed at auctions and the lowest on the electronic trading platform. However, except for the electronic venue, the relatively high price discounts at auctions or in the OTC market may be offset by the case effect, that is, positive price premiums for trading wines in 6- or 12-bottle cases.

Finally, we provide some technical results concerning price dispersion and tail characteristics obtained during the simulation procedure (Table 10), with tau describing precision and degrees of freedom. The findings reveal large price dispersion in transaction prices around the mean value. The deviations differ between the trading systems analyzed, with the smallest being in the Liv-ex market, followed by the OTC market, and the largest occurring at auctions. All of the distributions have fat tails.

\section{Discussion}

The results provide a set of interesting insights about the process of fine wine price formation across the specified trading venues. 
In particular, auctions, an electronic exchange (Liv-ex), and the OTC market provide diverse valuations since they attract or are accessible to diverse types of traders. Auctions, offering the highest unobserved value of wine, defined by the $\beta$ ( $m$ ) parameter, seem to be mostly dominated by retail traders who make low-volume trades. Therefore, they are highly exposed to the influence of intermediating auctioneers, who aim at maximizing their own profits and who are therefore likely to favor higher wine pricing (Ashenfelter, 1989). Conversely, an electronic exchange is targeted at informed traders interested in high-volume trading, which implies lower price levels due to an increased scale of operation. Interestingly, the relationship between the auction prices and the equivalent Liv-ex prices corresponds to the price relationship indicated by Czupryna and Oleksy (2018) for both trading venues. Whether the fact that the lowest level of valuations is found in the OTC market is due to the larger number of informed traders active in this venue, their greater negotiating flexibility, or their substantial informational advantage over retail traders, is difficult to answer, owing to the unknown structure of traders and the unidentifiable transaction origin.

All wine producers considered in this study belong to the same reputation class. However, some dissimilarities in business management, vineyard size, production volumes, as well as in customer preferences and their attitude towards the brand, may translate into differences in wine prices. Specifically, the highest price premiums for Lafite Rothshild, also confirmed by Cardebat et al. (2017), may be linked to the unique interest of investors in this wine and the phenomenon of a "Lafite bubble," as suggested by Breeden and Liang (2017).

Furthermore, the age (aging) effect leads to relatively higher prices at auctions than on the Liv-ex exchange or OTC markets, possibly due to the potentially greater importance of wine age (as a price determinant) to private collectors than professional wine traders, and also to the higher non-financial benefits it provides them over time, as suggested by Dimson, Rousseau, and Spaenjers (2015). Its impact may be further altered after segmenting wines into specific age groups, depending on the life cycle phase or historical connotations. Interestingly, the inter-venue differences reveal that relatively higher maturity premiums may be associated with trading on the electronic exchange, where wine traders are likely to trade at higher prices in response to increased demand from their B2B clientele (e.g., restaurants) and affluent end consumers. Accordingly, higher novelty premiums observed in the OTC market or at the auction venue may be linked to the desire of retail traders or investors to add fresh vintages to their private wine portfolios, accompanied by expectations for their growth in value. In the case of the auction venue, the apparent tendency to favor recent over past vintages is in line with the findings of Cardebat et al. (2017).

Correspondingly, the analysis of the quality effect reveals the near-linear relationship between prices and wine ratings, with the strongest association being observed at auctions. This indicates that retail traders may attach greater importance (or maybe more susceptible to) expert endorsements than institutional traders 
are. Therefore, retail traders at auctions are likely to behave as uninformed traders, whereas professional traders may act as informed traders. The OTC market is occupied by a mixture of them (in an indeterminate proportion).

Furthermore, the total impact of the bottle size is positive for large formats and is generally strongest on the electronic exchange, due to the high level of product standardization, while being weakest at auctions, where traders may have more interest in completing a vintage collection rather than in assembling a broad spectrum of bottle formats. Nonetheless, the bottle atypicality itself has a negative price impact across all the trading venues, which suggests the customer's inclination toward typical products. This result should not be surprising, as the $750 \mathrm{ml}$ is the most popular bottle size in the wine market (Brunke et al., 2009).

As anticipated, increased transaction volumes raise expectations for unit price reductions in all the trading venues. Interestingly, at auctions where lot sizes and transaction volumes are relatively small and typically limited to single or assorted bottles, traders expect higher price discounts for an increase in the volume in comparison to other venues. However, this negative price-volume relationship does not fully hold after controlling for the case effect (defined by the use of 6- and 12-bottle case packaging). Retail traders or collectors may treat lots with complete cases as non-standard or exceptional trades and thus are likely to pay more for this wine attribute. This case premium may also be associated with greater confidence in product authenticity and its "trophy value," as suggested by Cardebat et al. (2017). Analogous interaction of the transaction volume effect and the case effect, albeit on a smaller scale, is noticeable on the OTC market. It is only on the electronic trading venue, where relatively large volumes are subject to trade, and where case packaging is one of the fundamental requirements to be met in order to conclude a standard (not special) contract that increased transaction volumes and case packaging engender substantial price discounts.

Finally, each trading venue exhibits a slightly different price variation. Retail traders and investors at auctions generate the highest price fluctuations due to the pronounced information asymmetry among market participants, increased uncertainty as to auction results, or heightened emotions while bidding. In turn, an electronic exchange offers the smallest price dispersion around the mean value, which should not come as a surprise since it is mostly informed traders who conduct transactions in this particular venue. Nevertheless, all observed variation levels are relatively high, which is rather characteristic of the wine market (Jaeger and Storchmann, 2011) and may be derived from its general inefficiency (Bouri, Chang, and Gupta, 2017).

Nevertheless, our results suffer from several limitations. First, the auction and OTC venues are not internally homogenous markets, as they involve diverse trading platforms, trading terms and conditions (e.g., transaction costs), and various types of traders. Moreover, both markets are not identifiable in terms of transaction type (B2B or B2C) and trader motivations. This makes an inter-venue 
price comparison reasonable under the assumption that emotionally-driven wine traders primarily operate at the auction venue, with well-informed profit-driven traders preferring the electronic exchange and a mix of them (in unknown proportions) trading on the OTC venue. Accurate identification of traders might provide changes in the data classification and modeling outputs. Second, the Liv-ex index, used for estimating the unobserved value of wine, does not cover all vintages that are subject to the analysis. Alternative indices, as suggested by Masset and Weisskopf (2018) or the index extension (Cardebat et al., 2017), could be considered for this purpose. Third, the division of wine vintages into groups is a challenging task, owing to evident variation in their quality. Thus, the analysis of the age effect at an aggregated level requires additional assumptions. Ashenfelter's (2008) approach or a system of rating pooling (Lecocq and Visser, 2006) could support vintage grouping.

\section{Conclusion}

This research aims to assess how various wine attributes (producer, wine age, quality, bottle size, case, flaws, and transaction volume) affect prices in three types of trading venues: auctions, an electronic exchange, and the OTC market. To do this, a Bayesian approach has been employed, which represents a noteworthy alternative to the hedonic or repeat-sales regressions that are typically used for analyzing price behavior in the fine wine market.

The most important outcome of our study refers to the role of various trading venues in fine wine trading. As the market evolves in response to ongoing globalization and trade digitalization, leading to increased complexity in the structure of the fine wine market and necessitating the coexistence of many competitive trading venues, the selection of the optimal venue becomes a strategic decision for wine traders.

Essentially, we find inter-venue price differentiation and intra-venue price dispersion, which may be linked to both differences in the trading mechanism and trader heterogeneity across venues. The strength and direction of the examined effects are consistent with both initial expectations and the empirical evidence.

The growing importance of electronic trading will likely cause further changes in the structure and functioning of the fine wine market and serve to increase competition between trading venues. Therefore, examining the price behavior in a multimarket setting deserves special attention.

\section{References}

Ashenfelter, O. (1989). How auctions work for wine and art. Journal of Economic Perspectives, 3(3), 23-36. 
Ashenfelter, O. (2008). Predicting the quality and prices of Bordeaux wine. Economic Journal, 118(529), F174-F184.

Ashenfelter, O., and Storchmann, K. (2010). Measuring the economic effect of global warming on viticulture using auction, retail and wholesale prices. Review of Industrial Organization, 37(1), 51-64.

Blijlevens, J., Carbon, C. C., Mugge, R., and Schoormans, J. P. (2012). Aesthetic appraisal of product designs: Independent effects of typicality and arousal. British Journal of Psychology, 103(1), 44-57.

Bouri, E., Chang, T., and Gupta, R. (2017). Testing the efficiency of the wine market using unit root tests with sharp and smooth breaks. Wine Economics and Policy, 6(2), 80-87.

Boyer, K., and Verma, R. (2009). Operations and Supply Chain Management for the 21st Century. Mason, OH: Cengage Learning.

Breeden, J. L., and Liang, S. (2017). Auction-price dynamics for fine wines from age-periodcohort models. Journal of Wine Economics, 12(2), 173-202.

Brunke, H., Thiemann, F., Mueller, R. A., and Albrechts, C. (2009). Odd prices for odd bottles at VDP auctions? Paper presented at Enometrics XVI Conference of the Vineyard Data Quantification Society, May 20-23, Namur, Belgium.

Burton, B. J., and Jacobsen, J. P. (2001). The rate of return on investment in wine. Economic Inquiry, 39(3), 337-350.

Cardebat, J. M., Faye, B., Le Fur, E., and Storchmann, K. (2017). The law of one price? Price dispersion on the auction market for fine wine. Journal of Wine Economics, 12(3), 302-331.

Cardebat, J. M., Figuet, J. M., and Paroissien, E. (2014). Expert opinion and Bordeaux wine prices: An attempt to correct biases in subjective judgments. Journal of Wine Economics, 9(3), 282-303.

Carroll, R., and Vallen, B. (2014). Compromise and attraction effects in food choice. International Journal of Consumer Studies, 38(6), 636-641.

Chandon, P., and Ordabayeva, N. (2009). Supersize in one dimension, downsize in three dimensions: Effects of spatial dimensionality on size perceptions and preferences. Journal of Marketing Research, 46(6), 739-753.

Cyr, D., Kwong, L., and Sun, L. (2019). Who will replace Parker? A copula function analysis of Bordeaux en primeur wine raters. Journal of Wine Economics, 14(2), 133-144.

Czupryna, M., Jakubczyk, M., and Oleksy, P. (2020a). Price formation in parallel trading systems: Evidence from the fine wine market. Journal of Artificial Societies and Social Simulation, 23(3), 1-11.

Czupryna, M., Jakubczyk, M., and Oleksy, P. (2020b). Order book dynamics of fine wine exchange. Journal of Wine Economics, 15(4), 403-411.

Czupryna, M., and Oleksy, P. (2018). The effect of an electronic exchange on prices and return volatility in the fine wine market. e-Finanse, 14(4), 22-35.

De Jong, F., and Rindi, B. (2009). The Microstructure of Financial Markets. New York: Cambridge University Press.

Dimson, E., Rousseau, P. L., and Spaenjers, Ch. (2015). The price of wine. Journal of Financial Economics, 118(2), 431-449.

Di Vittorio, A., and Ginsburgh, V. (1996). Des enchères comme révélateurs du classement des vins: Les grands crus du Haut-Médoc. Journal de la Société de Statistiques de Paris, 137(2), $19-49$.

Dubois, D., Rucker, D., and Galinsky, A. (2012). Super size me: Product size as a signal of status. Journal of Consumer Research, 38(6), 1047-1062. 
Espejel, J., Fandos, C., and Flavian, C. (2007). The role of intrinsic and extrinsic quality attributes on consumer behavior for traditional products. Managing Service Quality, 17(6), 681-701.

Faye, B., and Le Fur, E. (2019). On the constancy of hedonic wine price coefficients over time. Journal of Wine Economics, 14(2), 182-207.

Fernandez-Perez, A., Frijns, B., Tourani-Rad, A., and Weisskopf, J. P. (2019). Behavioural heterogeneity in wine investments. Applied Economics, 51(30), 3236-3255.

Fox, K. J., and Melser, D. (2014). Non-linear pricing and price indexes: Evidence and implications from scanner data. Review of Income and Wealth, 60(2), 261-278.

Georgantzís, N., and Tisserand, J. C. (2019). The role of individual risk attitudes on old wine valuations. Journal of Wine Economics, 14(4), 417-426.

Hull, J. C. (2018). Options, Futures, and Other Derivatives, $10^{\text {th }}$ edition. New York: Pearson Education.

Jaeger, D. A., and Storchmann, K. (2011). Wine retail price dispersion in the United States: Searching for expensive wines? American Economic Review, 101(3), 136-141.

Jones, G. V., and Storchmann, K.-H. (2001). Wine market prices and investment under uncertainty: An econometric model for Bordeaux Crus Classes. Agricultural Economics, 26(2), 115-133.

Kruschke, J. K. (2014). Doing Bayesian Data Analysis: A Tutorial with R, JAGS, and Stan. New York, NY: Academic Press.

Lecocq, S., and Visser, M. (2006). Spatial variations in weather conditions and wine prices in Bordeaux. Journal of Wine Economics, 1(2), 114-124.

Liv-ex (2019). Membership terms. Available at: https://www.liv-ex.com/liv-ex-membershipterms/ (accessed August 2, 2019).

Luxen, M. F. (2018). Consensus between ratings of red Bordeaux wines by prominent critics and correlations with prices 2004-2010 and 2011-2016: Ashton revisited and expanded. Journal of Wine Economics, 13(1), 83-91.

Lynn, M. (1989). Scarcity effects on desirability: Mediated by assumed expensiveness? Journal of Economic Psychology, 10(2), 257-274.

Madhani, P. M. (2017). Logistics and marketing integration: Enhancing competitive advantages. IUP Journal of Management Research, 16(3), 7-29.

Madhavan, A. (2000). Market microstructure: A survey. Journal of Financial Markets, 3(3), 205-258.

Masset, P., and Weisskopf, J. P. (2018). Wine indices in practice: Nicely labeled but slightly corked. Economic Modelling, 68, 555-569.

Masset, P., Weisskopf, J. P., and Cossutta, M. (2015). Wine tasters, ratings, and en primeur prices. Journal of Wine Economics, 10(1), 75-107.

Morozova, K., Schmidt, O., and Schwack, W. (2015). Effect of headspace volume, ascorbic acid and sulphur dioxide on oxidative status and sensory profile of Riesling wine. European Food Research \& Technology, 240(1), 205-221.

Niklas, B., and Rinke, W. (2020). Pricing models for German wine: Hedonic regression vs. machine learning. Journal of Wine Economics, 15(3), 284-311.

Oczkowski, E. (2016). Hedonic wine price functions with different prices. Australian Journal of Agricultural and Resource Economics, 60(2), 196-211.

Outreville, J. F. (2011). Does the bottle size matter? An investigation into differences between posted and market price. American Association of Wine Economists, Working Paper No. 86. Available at https://wine-economics.org/wp-content/uploads/2012/10/ AAWE_WP86.pdf. 
Prelec, D., Wernerfelt, B., and Zettelmeyer, F. (1997). The role of inference in context effects: Inferring what you want from what is available. Journal of Consumer Research, 24(1), 118-125.

Robert Parker Wine Advocate (2018). The Wine Advocate Vintage Guide 1970-2015. Available at www.robertparker.com (accessed September 13, 2018).

Schamel, G., and Anderson, K. (2003). Wine quality and varietal, regional and winery reputations: Hedonic prices for Australia and New Zealand. Economic Record, 79(246), 357-369.

Shapiro, C. (1983). Premiums for high quality products as returns to reputations. Quarterly Journal of Economics, 98(4), 659-679.

Stevens, S. S. (1986). Psychophysics: Introduction to Its Perceptual, Neural, and Social Prospects. Oxford: Transaction Books.

Storchmann, K. (2012). Wine economics. Journal of Wine Economics, 7(1), 1-33.

Terrien, C., and Steichen, D. (2008). Accounting for social taste. Application to the demand for wine. International Journal of Wine Business Research, 20, 260-275.

Tolhurst, T. (2019). Model-free detection of a speculative asset bubble: Evidence from the world market for superstar wines. Available at http://ses.wsu.edu/wp-content/uploads/ 2020/01/Publication-1.pdf (accessed December 12, 2019).

van Herpen, E., Pieters, R., and Zeelenberg, M. (2014). When less sells more or less: The scarcity principle in wine choice. Food Quality \& Preference, 36, 153-160.

Wankhede, L., and Dabade, B. (2010). Quality Uncertainty and Perception: Information Asymmetry and Management of Quality Uncertainty and Quality Perception. Berlin/ Heidelberg, Germany: Springer-Verlag.

Zimberoff, L. (2018). Investing in fine wine is more lucrative than ever. Available at https:// www.bloomberg.com/news/articles/2018-07-19/why-the-best-investment-vehicle-is-oneyou-can-drink (accessed August 02, 2019). 